\begin{tabular}{c} 
International Journal of Engineering \& Technology, 7 (4.38) (2018) 980-983 \\
International Journal of Engineering \& Technology \\
SPC \\
Website www.sciencepubco.com/index.php/IJET \\
Research paper \\
\hline
\end{tabular}

\title{
Environmental Management Influence for Shade Trees on the temperature Reduction of yhe building.
}

\author{
Thanawuth Khunthong
}

Phranakhon Rajabhat University, Department of Architecture, Bangkok- THAILAND

\begin{abstract}
Thailand is located in a humid tropical climate and near the equator. Thus the average air temperature is high throughout the year. Environmental factors factors such as the sun, wind and humidity affects residential buildings especially, heat from the sun is a main factor, which leads a problems of heat inside the buildings (Prawewan Amornpong, 2001). Therefore, Installing air conditioning inside the buildings is the solution for this problem. However, from the study on the properties of plants it was found that plants are effective in blocking the sun's rays as well as effectively maintaining the air temperature in the area (Soontorn Boonyathikarn, 1999). So, planting trees to prevent the sunlight, as shade to reduce sun heat in the buildings should be an approach, which could be adopted to decrease the use of air conditioning and also energy consumption in buildings (Trungjai Buranasompob, 2000). This research aims (1) to study and create design guidelines on landscape models which conforms to the environment of sunlight and wind in the central region of Thailand and (2) to propose the guidelines on architectural landscape designs and plants' setting around the buildings in 8 directions; North (N), Northeast (NE), East (E), Southeast (SE), South (S), Southwe st (SW), West (W) and Northwest (NW). The results found that the landscape model included the setting on plants as shade at all sides of the building envelope during 08.00-17.00 PM of the day throughout the year. These can reduce the air temperature of the building envelope as well as the average temperature inside the buildings, this showed a decrease in temperature by as much as $3.95^{\circ} \mathrm{C}$ or $13.478 \%$ compared with the average exterior air temperature of the buildings throughout the year.
\end{abstract}

Keywords: Architecture, Environment, Landscape, Plants

\section{Introduction}

Thailand is located in a humid tropical climate and near the equator. Thus the average air temperature is high throughout the year. Environmental factors such as the sun, wind and humidity affects residential buildings especially, heat from the sun is a main factor, which leads to problems of heat inside the buildings (Prawewan Amornpong, 2001). Therefore, Installing air conditioning inside the buildings is the solution for this problem. However, a study on the properties of plants it was found that plants are effective in blocking the sun's rays as well as effectively maintaining the air temperature in the area (Soontorn Boonyathikarn, 1999). So, planting to prevent the sunlight, as shade to reduce sun heat in the buildings should be an approach which could be adopted to decrease the use of air conditioning and also energy consumption in buildings (Trungjai Buranasompob, 2000).

The Aim of Research

1) The physical properties of trees, which influence to modify micro-climate.

2) The factors and the important group of variables on trees which are the most potential to modify micro-climate of houses to be comfort zones.

3) Model of Architectural Landscape conforms to Environment for Air Temperature Reduction of the Building Envelope.

\section{Experimental details}

1) This research was carried out only on trees, due to trees being the most efficient way to decrease the violence of the temperature during the day. (Soontorn Bunyatikarn, 1999)

2) This research studied on the kinds of trees: 1) auspiciousness trees 2) local trees (selected by using criterion from the analysis of trees' properties at maturity table) (Auomporn Weesommai and Board, 1999). which is studied only on a micro-climate modifier.

3) This research studied on houses in the central part of Thailand.

4) The collection, measurement, testing and comparison of the data during the summer season.

5) The collecting data equipment in each place, at the same time, needs to report the same results or could calibrate in the same standard.

The variables of the research:

1) Factors on trees which influence to modify micro-climate

1.1 Species of the studied trees

1.2 Physical properties of the studied trees ;

- Form - Height at maturity

- Spread - Density

- Periodicity - Height from under the Shrub

to the bottom

1.3 Shade

1.4 Environmental factors of the studied Thai houses ;

- Air temperature - Relative humidity

- Sun path, Air velocity - Mean radiant temperature

2) Factors on thermal comfort zone ;

- Air temperature - Relative humidity

- Air velocity - Mean radiant temperature 
Method of Research

1) Review of literature and related documents. Study the information on trees, Thai houses, environment and criterion on comfort zones, which influences and modifies the micro climate.

2) Collect the data in summer season from 6 am to $6 \mathrm{pm}$

2.1) Data of trees; Species of the studied trees, Periodicity, Physical properties of the studied tree, Shade.

2.2) Data collection on environmental factors. Measure the variables hourly in the summer season, from $6 \mathrm{am}$ to $6 \mathrm{pm}$ daily, per month by using Data logger system 2000. The Globe temperature will be used to measure the mean radiant temperature.

(1) Measure the variable of trees;

- Air temperature

- Relative humidity

-Mean radiant temperature

- Temperature on shade

(2) Measure the environmental variable of the studied houses ;

- Air temperature

- Relative humidity

-Mean radiant temperature

2.3) Data collection on sun path direction and air velocity direction which appear on the studied houses.

3) Analysis and evaluation on collected environmental factors and the variable. Analysis and comparison will be used to identify the important variable of trees which influence and modifies microclimate of houses. Rearrange the importance of the variable and classify the group of variable.

4) Synthesize for identifying factors and the group of important variables, which is the most potential for micro-climate modifier to thermal comfort of houses. The results will be presented in 3 seasons, 8 directions.

5) The model is created from the factors and the combination of the group of the important variables. The model is used to inspect the influence of micro-climate modifier to the thermal comfort of houses.

6) Evaluation model by using Bioclimatic chart which is the instrument for comparing the differences between the results on the environmental management of houses by using trees and the environment of the houses without trees growing.

7) Summarized results and guidelines are designed for microclimate modifier in the most valuable methods. The guidelines are presented in the species and position of trees in 8 directions.

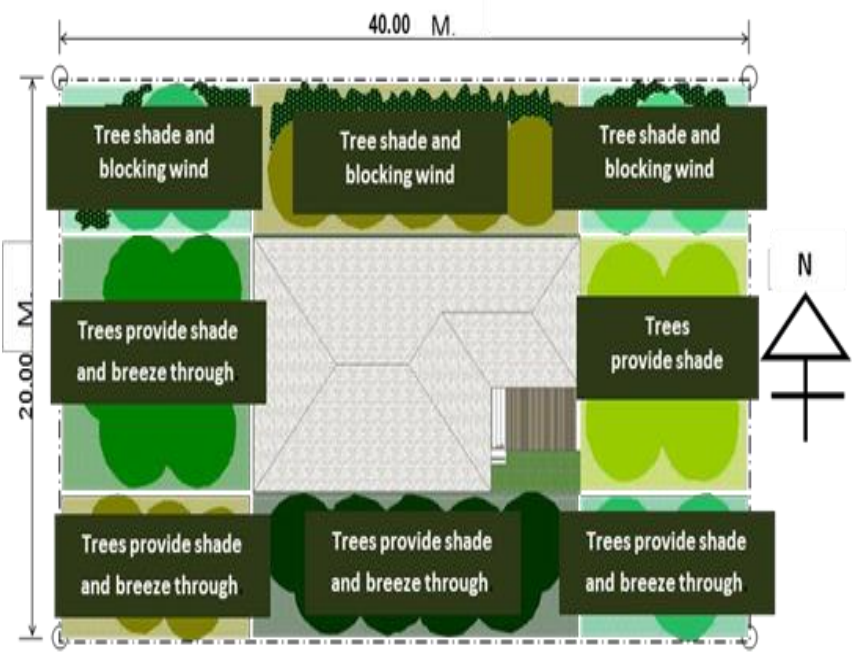

Fig. 1: Model management environment for shade trees on The temperature reduction of the building.

\section{Results and discussion}

1) Physical properties of the studied trees, which influence and modify micro-climate.
2) Factors and the combination of the group of important variables and influence of micro-climate modifiers to thermal comfort of houses.

3) Pattern of design guidelines, which are the environmental management concept.

The variable and factors on trees in 8 directions are used to modify micro-climate modifiers in the most valuable methods.

Model of trees planting to create shade for housing to day: case study on general housing with single storey and high platform in the area of 800 square meters. The results of the study were concluded by the 3 models of tree planting around the house with the following recommendations

(Figure 1.)

A) Wall on the north side. Northeastern and northwest. The plants were grown oval. Bush thick to shield the wind. There are at least 5.50 meters 10.00 meters planted on the far wall.

B) The east and southeast. The plants were grown round Moderate to dense bush leaves. Bush leaves the stage and open to the wind. There are at least 6.50 meters 10.00 meters planted on the far wall.

C) South, southwest and west to plant trees sphere. Bush leaves the dense Bush leaves the stage under a high wind and airy, with a height of at least 15.00 meters, 8.00 meters planted on the far wall.

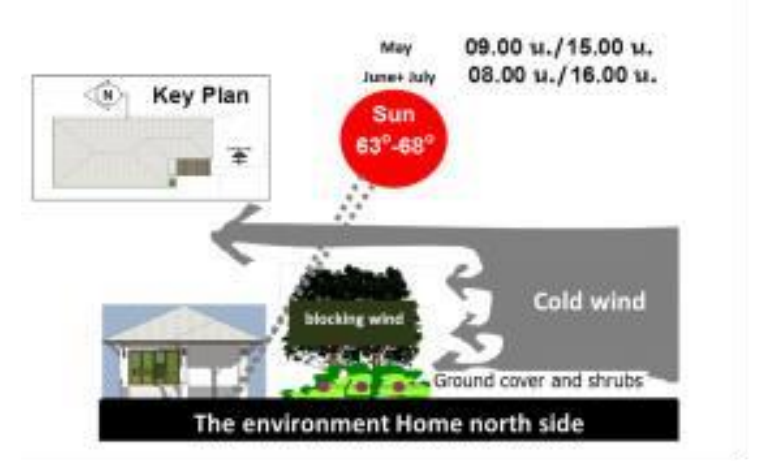

Fig. 2: North Side

1) Wall on the north side plants were grown elliptical canopy height $\geq 10$ meters radius $\geq 3.50 \mathrm{~m}$ canopy dense foliage dense bush. Do not leave the winter Planting distance from the wall at a right angle (a1) was 5.50 meters tall shrub planting and wind protection. (Figure 2.)

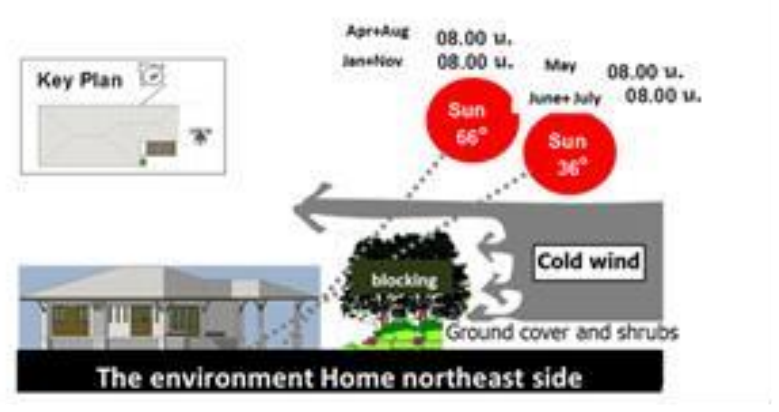

Fig. 3: $\mathrm{N}$ or t he a s t Side

2) The northeast wall plants were grown elliptical canopy height $\geq$ 10 meters radius $\geq 3.50 \mathrm{~m}$ canopy dense foliage dense bush. Do not leave the winter Planting distance from the wall at a right angle (a1) was 5.50 meters tall shrub planting and wind protection. (Figure 3.) 


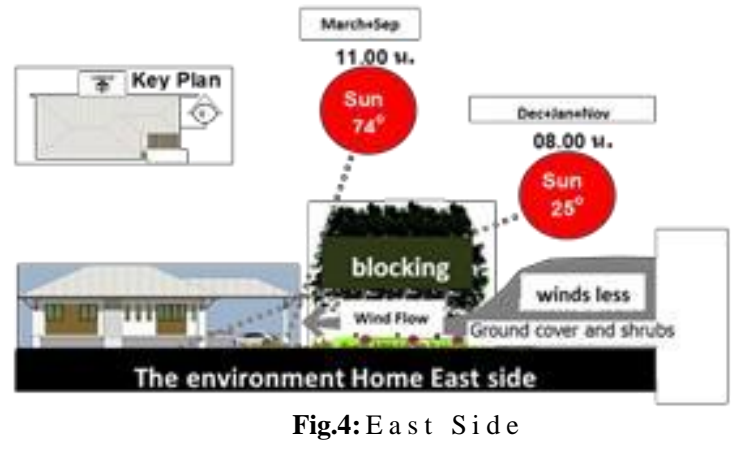

3) The east wall should plant trees medium round canopy height, canopy $\geq 10$ meter radius $\geq 3.50$ m moderately dense bush leaves. Bush leaves the stage and open to the wind. Planting distance from the wall at a right angle (a1) of $5.00 \mathrm{~m}$, planted shrubs. Wood mulch or grass to MRT surrounding area. (Figure 4.)

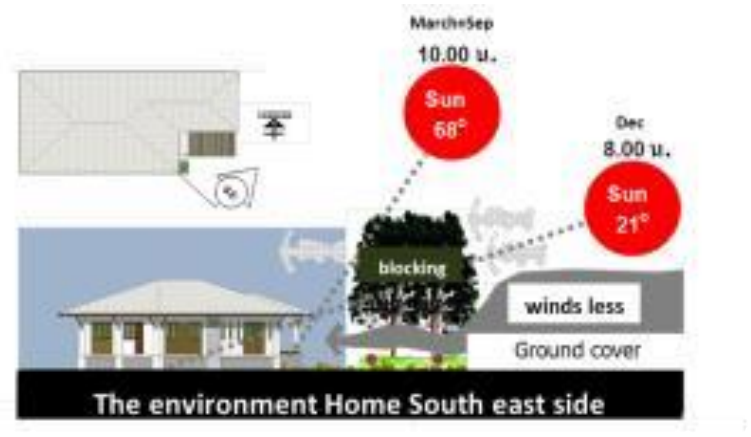

Fig.5: Southeast Side

4) The walls of the southeast should be planted vegetation canopy height $\geq 10 \mathrm{~m}$ radius circular canopy $\geq$ $3.50 \mathrm{~m}$ moderately dense bush leaves. The shapely shrub leaves to the wind. Planting distance from the wall at a right angle (a1) of 6.50 meters, grouping plants flowing the wind to the house and basement. Should be planted bushes, ground cover or grass to MRT surrounding area. (Figure 5.)

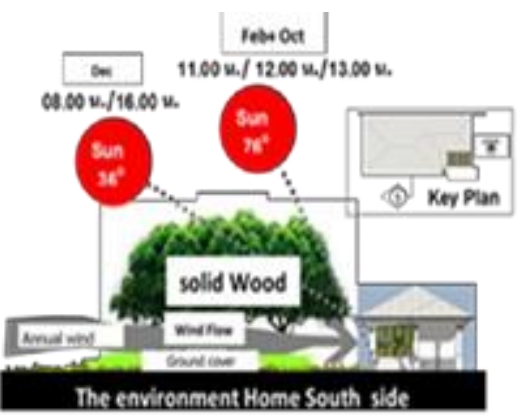

Fig. 6: South Side

5) Wall on the south side should be planted vegetation canopy height $\geq 15 \mathrm{~m}$ radius circular canopy $\geq 5$ meters thick shrubs, evergreen shrub leaves flowing the wind. Planting distance from the wall at a right angle (a1) of $8.00 \mathrm{~m}$ should be planted bushes, ground cover to reduce MRT surrounding area. (Figure 6.)

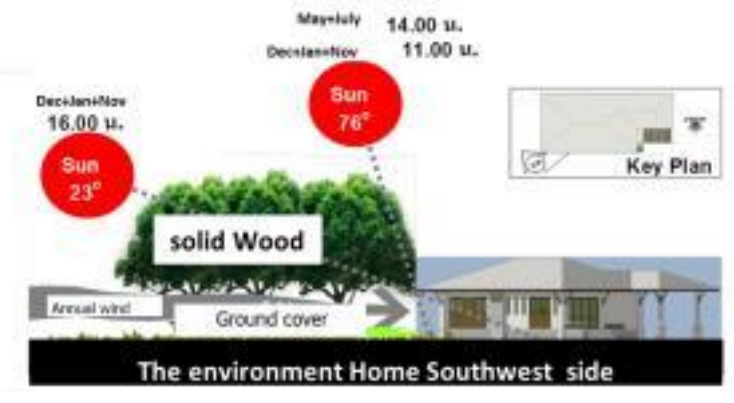

Fig.7: Southwest Side

6) Wall on the Southwest should be planted vegetation canopy height $\geq 15 \mathrm{~m}$ radius circular canopy $\geq 5$ meters thick shrubs, evergreen shrub leaves flowing the wind. Planting distance from the wall at a right angle (a1) of $8.00 \mathrm{~m}$ should be planted shrubs. Wood mulch or grass to MRT surrounding area. (Figure 7.)

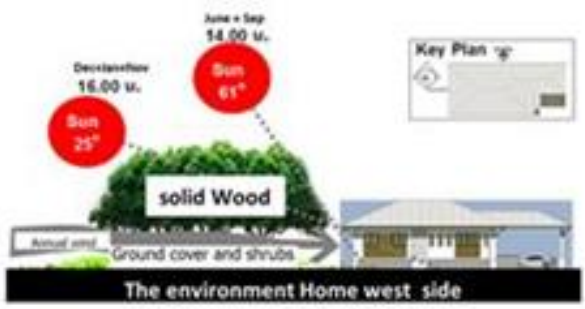

Fig. 8: West Side

7) The wall on the West side should be planted vegetation canopy height $\geq 15 \mathrm{~m}$ radius circular canopy $\geq 5$ meters thick shrubs, evergreen shrub leaves flowing the wind. Planting distance from the wall is equal to 8.50 square meters should be planted shrubs. Wood mulch to reduce MRT surrounding area. (Figure 8.)

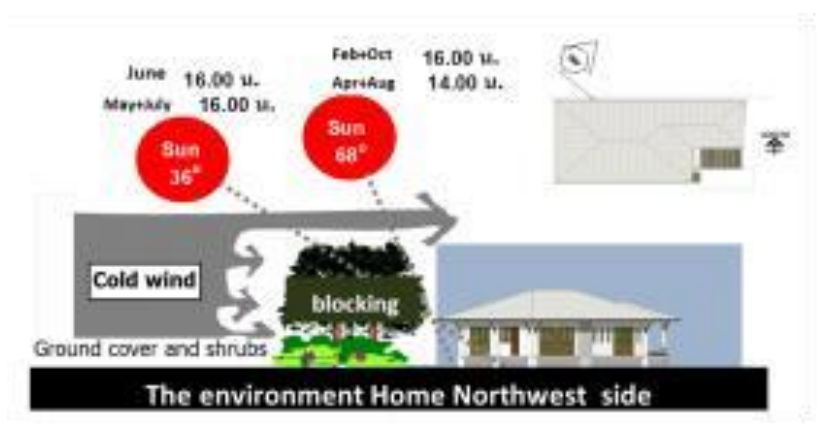

Fig. 9: Northwest Side

8) The wall of the northwest plants were grown elliptical canopy height $\geq 10$ meters radius $\geq 3.50 \mathrm{~m}$ canopy dense foliage dense bush. Do not leave the winter Planting distance from the wall angles of 5.50 meters and a shrub plant block winter winds. (Figure 9.)

\section{Conclusions}

The landscape model included the setting of plants as being shades of all sides of the building envelope during 08.00-17.00 of the day throughout the year. These can reduce the air temperature of the building envelope as well as the average temperature inside the buildings. The temperatures decreased $3.95^{\circ} \mathrm{C}$ or $13.478 \%$ compared with the average exterior air temperature of the buildings throughout the year.

\section{Acknowledgments}

Thank you to the Research and Development Institute and the administrators of Phranakhon Rajabhat University for the support 
to this research. Thank you all the establishments for providing information in this research.

\section{References}

[1] Prawewan, A. Adjusting the environment around the building with natural plant materials to create thermal comfort. Thesis Master of Architecture. Bangkok : KMITL. (2001).

[2] Ruthai, J., Thai Traditional House. Bangkok : The Association of Siamese Architects under Royal Patronage. (1996).

[3] Soontorn, B., Home energy-saving design techniques to better quality of life. (1999).

[4] S oontorn, B.\& Bundit, E., Applied research includes designing energy-efficient buildings. 1st edition. Bangkok: energy Research Institute Chulalongkorn University. (1996).

[5] Somjit, Y., Material plants for landscaping. 1st edition. Bangkok: Sukhothai Thammatirat Kingdom. (1997).

[6] Satein, K., Traditional Thai plant, Phranakhon: Bunnakorn. (1964).

[7] Trungjai, B., Tropical Architectural design in Thailand. Bangkok silpakorn university. (2000).

[8] Urakin, V.\& Board. TamraPromchatChabubLuang. Phranakhon: Publisher of Look S.Tammapakdee. (1960).

[9] Auomporn, W. \& Board. (1999). Plants in the Landscape Architecture. Bangkok:Pimdee

[10] Olgyay, V., Design with climate. New Jersey : Priston University Prett. (1973).

[11] Stein, B., Mechanical and Elastically equipment for building 7th Edition, John Wiley and son, New York. (1982). 